\title{
El fracaso de la modernización democrática, 1956-1962 ${ }^{1}$
}

María Estela Spinelli

Resumen: El texto analiza la construcción del proyecto desarrollista en el contexto de la segunda fase de la crisis política argentina que siguió al triunfo de la Revolución Libertadora. Atiende a sus objetivos y sus condicionantes. Revisa, en una primera instancia, la elaboración de la estrategia política de integración del peronismo a la legalidad política durante el gobierno revolucionario, lo que le permitió ganar las elecciones de 1958. En la segunda parte, busca explicar la puesta en práctica y recepción política, cultural y social del mismo, durante la gestión presidencial de Arturo Frondizi, hasta su etapa final.

Palabras clave:

\begin{abstract}
The text analyzes the construction of the developmental project in the context of the second phase of the Argentine political crisis that followed the triumph of the Liberating Revolution. It attends to its objectives and its conditioning factors. It reviews, in a first instance, the elaboration of the political strategy of integration of the Peronism to the political legality during the revolutionary government, which allowed him to win the elections of 1958. In the second part, it tries to explain the implementation and political reception, Cultural and social, during the presidential administration of Arturo Frondizi, to its final stage.
\end{abstract}

Keywords:

\section{Consideraciones previas}

En un campo temático que ha sido historiográficamente muy transitado y debatido y donde una nueva revalorización de la figura de Arturo Frondizi y del proyecto desarrollista vuelven a cobrar protagonismo en el ámbito político cultural actual, el objetivo de esta indagación es revisitar el contexto en el que emerge su candidatura y proyecto presidencial, como el de su gestión de gobierno entre 1958 y 1962. Nos cen-

\footnotetext{
${ }^{1}$ Trabajo recibido el 09/04/2017. Aceptado el 31/05/2017. La autora agradece la lectura y los comentarios de Eduardo Míguez.

${ }^{2}$ Investigadora del Instituto de Estudios Histórico-Sociales, la Universidad Nacional del Centro y la Universidad Nacional de Mar del Plata. Contacto: mariaestelaspinelli@gmail.com
} 
tramos en dos interrogantes simples, ¿cómo triunfó?, y ¿por qué, en su momento, fracasó el controvertido proyecto implementado? El pacto con Perón y el voto peronista resultaron importantes para el primero. La fuerte resistencia ideológica y política de amplios sectores civiles y de un importante sector de la oficialidad de las fuerzas armadas a los cambios implementados, en los ámbitos político, económico y en el manejo de las relaciones internacionales, contribuyeron al segundo.

$\mathrm{El}$ argumento que vamos a desarrollar para explicar este proceso parte de la siguiente conjetura: El proyecto desarrollista, elaborado en el período como herramienta para superar la crisis política originada en el enfrentamiento peronismo antiperonismo, desafió abiertamente al segundo granjeándose su oposición y el desconocimiento de su legitimidad. Además, puso en un primer plano la transformación de la economía, con una serie de propuestas ajenas a la tradición política argentina, tanto en sus vertientes liberal como nacionalista y de izquierda, aunque combinó elementos de todas ellas. ${ }^{3}$ Más aún, el proyecto rechazó los principios intervencionistas y antiimperialistas vigentes en el radicalismo, como en una significativa parte del arco político antiperonista, y atentó además contra las políticas sociales y económicas más populares y extendidas del peronismo. ${ }^{4}$ A todo esto se sumó que sus políticas fueron enfrentadas por un nuevo detractor, la naciente izquierda revolucionaria que empezaba a mirarse en el espejo cubano, lo cual introdujo un nuevo conflicto que arrasó con la legalidad buscada.

El tratamiento del tema se estructura en dos bloques temporales. El primero remite a los años de la Revolución Libertadora, desde el fin del enfrentamiento bélico hasta la salida electoral de febrero de 1958. Analiza los conflictos y el clima políticos. El segundo, siguiendo los mis-

\footnotetext{
${ }^{3}$ «La tentativa de estructurar una nueva coalición nacional-populista-liberal: 1958-1962» titulan al análisis de esa experiencia Mallon y Sourrouile, (1973) El desarrollismo como estrategia de consolidación y expansión del capitalismo en los países industrialmente rezagados, estaba en la agenda económica occidental desde los años inmediatos al fin de la Segunda Guerra Mundial. En líneas generales promovía una importante inversión de capitales en los rubros industriales básicos, energía, transporte e industria pesada. El primer proyecto desarrollista puesto en marcha en América Latina, fue el de Juscelino Kubistchek en Brasil, entre 1956-61, denominado Plan de metas. Un análisis en perspectiva comparada en Sikkin, (2009). En una investigación más reciente, Jáuregui explora en las continuidades y rupturas de algunos problemas con el peronismo y el Plan Prebisch, Jáuregui, Cerra y Yazbec, (2016): 15 a 45 .

${ }^{4}$ Bustos Fierro, (1969): 383 y s.s., Guardo (1963): 115 a 128, también Correspondencia Perón-Frigerio, 1958-1973 y D’Abate, (2003)
} 
mos tópicos, se centra en la gestión presidencial de Arturo Frondizi, desde el anuncio y puesta en marcha del programa desarrollista, hasta su derrocamiento a fines de marzo de 1962.

\section{Los conflictos políticos en los años de la Libertadora, 1955-1958. Un repaso de los hechos}

La euforia por el triunfo de la Revolución Libertadora fue efímera. Imponentes manifestaciones cívicas en la mayor parte de las ciudades del país festejaron la caída de Perón y la recuperación de las libertades y derechos. ${ }^{5}$ La asunción del Gobierno Provisorio integrado por el general Eduardo Lonardi y el contralmirante Isaac Francisco Rojas, que habían comandado las fuerzas del Ejército y de la Armada durante los hechos bélicos, se asentó, no obstante, sobre tensiones políticas subyacentes en diversos planos que pronto saldrían a la superficie.

En las Fuerzas Armadas, el proceso que culminó el 23 de septiembre contenía, al menos, dos revoluciones ${ }^{6}$ inspiradas en proyectos ideológicos y políticos antagónicos que estallaron tempranamente y se dirimieron en los primeros sesenta días de inaugurada esta etapa. El primero, de inspiración nacionalista, menos rupturista con el peronismo y al que adhirieron sectores del Ejército, propició el retorno al Estado de Derecho tratando de salvaguardar la paz política una vez retirado el expresidente Perón del centro de la escena. Inició un diálogo con el sindicalismo y anunció un rápido llamado a elecciones.

El intento pacificador del general Lonardi sintetizado en el lema «Ni vencedores ni vencidos» resultó inadmisible para quienes se consideraron actores decisivos de la victoria y genuinos portadores de los valores revolucionarios. ${ }^{7}$ Los altos mandos de la Marina obtuvieron el se-

\footnotetext{
${ }^{5}$ Spinelli, (2004).

${ }^{6}$ El periodista nacionalista Mariano Montemayor publicó en Cuadernos de Azuly Blanco un análisis de la coyuntura que tituló: «Las dos revoluciones del 16 de septiembre», Buenos Aires, 1956.

${ }^{7}$ Si bien sectores de la oficialidad del Ejército participaron activamente de la conspiración cívico-militar desde 1951 y muchos de ellos sufrieron prisión desde entonces, -ver memoria del general Lanusse, (1988)- la Marina fue mucho más homogénea en su oposición al gobierno peronista. Había sostenido sola el fracasado golpe de junio de 1955, cuando el ataque de la aviación naval dejó un saldo de más de trescientos muertos y setecientos heridos en la ciudad de Buenos Aires. La estrategia de septiembre, de avanzar desde la Base Naval de Puerto Belgrano, cercano a Bahía Blanca en la Provincia de Buenos Aires, resultó crucial en
} 
gundo término en la conformación del Poder Ejecutivo y espacios en el gabinete, invocaron la restauración de la tradición republicana y de los derechos y garantías constitucionales con la exclusión total del peronismo al considerar que la revolución debía ser «la tumba de la tiranía».

En los partidos políticos históricos las diferencias se plantearon en términos similares a los que dividían a las fuerzas armadas. Los partidos demócrata-liberales tradicionales, socialistas, demócratas y demócratas progresistas -interlocutores privilegiados del vicepresidente Rojas- reclamaron la restauración republicana, la incorporación del sistema electoral de representación proporcional que garantizara la representación de las minorías en la conformación del gobierno y la exclusión del peronismo de la vida política y sindical, como también de todo espacio de influencia dentro del aparato del Estado. A ellos se opusieron tempranamente los radicales del Movimiento de Intransigencia y Renovación que respondían al presidente del comité nacional de la UCR, Arturo Frondizi - por entonces, uno de los dirigentes más prestigiosos del país- que los acusaron de pretender recrear la Unión Democrática de 1946 y gestar un gobierno de minorías, a la par que se mostraron afines al discurso del general Lonardi de lograr alguna fórmula de sobrevivencia del peronismo y fundamentalmente del rápido llamado a elecciones. En medio de estos dos polos de la política legal, el resto de la UCR, crítica de su conducción partidaria, reivindicó la gesta revolucionaria calificándola de popular, democrática y antiimperialista.

En el flamante gobierno revolucionario, la lucha por la imposición de uno de los proyectos se planteó desde los primeros días y se libró en diversos escenarios cuando se comenzaron a discutir las primeras medidas concretas, desde la designación de ministros y funcionarios, la creación de la Junta Consultiva Nacional, las Comisiones de Investigadoras del Peronismo, la restitución de los órganos de prensa a sus propietarios y la disolución de la cadena de prensa del peronismo, entre muchas más. Todas ellas dieron lugar a enconados debates que mostraron la imposibilidad de conciliarlos y llevaron al desplazamiento del general Lonardi y su reemplazo en la presidencia por el general Pedro Eugenio Aramburu, con una presencia nominalmente más importante de la Marina en el Gobierno, que siguió conservando en la vicepresidencia al contralmi-

el desenlace de la batalla luego del bombardeo de los depósitos de combustibles de Mar del Plata y la amenaza al puerto de Buenos Aires. Dos relatos sobre esos sucesos, Perren, (1997) y González Crespo, (1993). 
rante Rojas, y un recorte, en la práctica, también nominal, de las atribuciones del presidente que cogobernaba, de ahí en más, con un Consejo Militar Revolucionario integrado por representantes de las tres armas con poder de veto sobre las decisiones del Ejecutivo, poco más adelante convertido en Junta Militar Consultiva, con facultades recortadas.

Después de dos meses aparecía derrotado el proyecto que sus críticos denominaron del «Peronismo sin Perón» y analistas políticos de la época caracterizaron como la lucha ideológica entre nacionalismo y liberalismo en el interior de la revolución. La Marina amplió su influencia, se aceleró el proceso de liberalización de la política y de proscripción y represión del peronismo y sus aliados nacionalistas y comunistas. ${ }^{8} \mathrm{El}$ Ejército se halló sometido al proceso de desperonización de sus filas, que afectó con el retiro y la baja a cientos de oficiales y alcanzó mayor número entre los suboficiales. ${ }^{9}$

Los partidos políticos se apresuraron a reconocer al nuevo presidente y ofrecerle su colaboración en el gobierno que éste retribuyó generosamente a través de cargos en los distintos niveles del Estado, entre los que fueron favorecidos radicales y conservadores $\mathrm{y}$, en menor medida, los minoritarios socialistas, miembros del nuevo partido Demócrata Cristiano y demócratas progresistas.

La construcción de consensos políticos dentro del gobierno provisorio siguió siendo una tarea ardua hasta el final del mismo. No lograron evitar, a lo largo de los dos años siguientes, que los conflictos internos, originados en muchos casos en la intransigencia antiperonista y anticomunista de la Marina, saltaran a menudo a los primeros planos de la prensa.

Los partidos finalmente lograron el espacio de diálogo y participación política que el peronismo les había negado durante su gobierno y Lonardi retaceado ${ }^{10}$ en los primeros sesenta días. Esto se concretó en el ámbito oficial a través de las Juntas Consultivas Nacional y Provinciales ${ }^{11}$ que asesoraron en cuestiones claves requeridas por el Poder Ejecu-

\footnotetext{
${ }^{8}$ El nuevo proyecto quedó plasmado en el Acta del 4 de diciembre de 1955, publicado en La Nación, 05/12/1955. Este introduce el objetivo de «Desmantelar el aparato totalitario» como eje de la política del gobierno revolucionario.

${ }^{9}$ Potash, (1981): 293 y s.s.

${ }^{10}$ En lo que se refiere, no a libertades, sino a participación política dentro del gobierno. Ver Spinelli, (2005): 96 a 108.

${ }^{11}$ Estas se conformaron durante la etapa presidencial del general Lonardi, aunque su actividad plena, en el ámbito nacional se desarrolló luego de la caída de éste.
} 
tivo, allí se debatieron el status legal del gobierno y sus atribuciones, la carta constitucional vigente en la etapa revolucionaria, que llevó a las propuestas de una nueva Reforma Constitucional que derogara la de 1949 y actualizara la Constitución de 1853, con sus reformas de 1860, 1866 y 1898, un nuevo Estatuto de los Partidos Políticos y otros, que tuvieron amplia difusión en la prensa. La mayoría de los partidos se pronunciaron por la desperonización y por una serie de medidas y reformas políticas que tendieran a asegurarla efectivamente en el largo plazo, entre las que sobresalía el proyecto de reforma del Régimen de Representación Electoral. ${ }^{12}$

Estos temas se fundamentaron en el balance que los actores realizaron de la experiencia vivida bajo el gobierno peronista. Este, a través de la concentración del poder y la vocación unanimista de su proyecto identificado con la nación, suprimió en los hechos los derechos políticos a los opositores - de reunión, de propaganda, de acceso a la prensa y al empleo público, de independencia de la Justicia- y practicó una vigilancia y persecución sistemática hacia ellos, tanto a través de las denuncias de miembros del Partido Peronista, o de sus amplias redes de militantes, organizaciones barriales, jefes de manzana y otros, sobre quienes formularan críticas o desobedecieran medidas, también por la acción del aparato de inteligencia del Estado e interviniendo las pocas comunas en las que éstos ganaron elecciones, a lo cual sumaron el culto y la celebración constante del presidente y de su esposa. A estas cuestiones se referían los antiperonistas, según revelan múltiples memorias y testimonios, cuando denunciaban a la tiranía que había dividido a la sociedad, implantado un régimen policíaco y vulnerado la república. ${ }^{13}$ Mientras los partidarios de Perón en general ignoraron o justificaron ese estado de cosas, denunciando los prejuicios clasistas de los opositores o como una valla legítima de defensa ante el temor a la pérdida de las conquistas sociales alcanzadas a manos de los representantes de la oligarquía y del privilegio, enemigos del pueblo y de la nación. ${ }^{14}$

\footnotetext{
12 Un análisis puntual del mismo en Spinelli, (2012).

${ }^{13}$ Entre ellos, García, (1971); Hardoy, (1993); Sánchez Zinny, (1958) y Goñi Moreno, (1967).

${ }^{14}$ Además de los argumentos desarrollados en la prensa oficialista hasta 1955, existe una vasta literatura política posterior a esa derrota de autores peronistas y filoperonistas, entre los que sobresalen además de las cartas y libros de Juan Domingo Perón,- Los Vendepatrias y la Fuerza es el derecho de las bestias- Jauretche, (1957), De Ferraris (1956), Pido la palabra, Ricardo Guardo (1963), y otros más.
} 
Como era inevitable, las posiciones inconciliables y la violencia política perduraron. Para la mayor parte de los partidos antiperonistas resultaba imposible reconstruir el régimen político democrático sin la exclusión política del peronismo que resultó proscripto y obligado a silencio, bajo amenaza de multas y prisión a quienes lo transgredieran ${ }^{15} \mathrm{a}$ lo que agregaron la inhabilitación e interdicción de dirigentes políticos y gremiales sospechados de corrupción, penas de prisión a los exlegisladores acusados de «traición a la patria» por haber otorgado poderes extraordinarios al Ejecutivo y un vasto operativo de persecución en todo el país.

El plan del gobierno revolucionario operó sobre dos aristas, una, tendiente a la reconstrucción del andamiaje político institucional que garantizara el retorno a la tradición democrática y republicana, a la que contribuyeron la mayor parte de los partidos representados en la Junta Consultiva Nacional y diversas organizaciones civiles, y otra, que llamaron destructiva, orientada a la eliminación del peronismo que dio por resultado un rebrote de la violencia. ${ }^{16} \mathrm{El}$ punto de mayor tensión fue el alzamiento y represión del 9 de junio de 1956, cuando en virtud de la puesta en vigencia del Toque de Queda, se aplicó la pena de muerte por fusilamiento a 31 hombres, militares y civiles implicados o supuestamente implicados en la sedición. ${ }^{17}$

La así llamada fase destructiva de la Revolución Libertadora convirtió al peronismo de opresor en víctima de la represión ${ }^{18}$ y contribuyó a debilitar el consenso antiperonista inicial por parte de quienes, más allá del rechazo a sus concepciones y prácticas políticas, reconocían su importante adhesión popular. Esta idea fue sostenida por los radicales del Movimiento de Intransigencia y Renovación y por otros grupos y

\footnotetext{
15 Según lo establecido por el Decreto Presidencial 4161/56.

16 Amaral, (1993).

${ }^{17}$ Varios escritos políticos y testimonios de contemporáneos hicieron referencia al fracasado «Levantamiento del General Valle», el 9 de junio de 1956, el Movimiento de Recuperación Nacional, que se convirtió en un hito de la épica de la resistencia peronista para la militancia posterior. Entre los más conocidos, Walsh, (1957) y Ferla, (1964). Aunque la prensa de la época hizo múltiples alusiones a la responsabilidad del expresidente Perón en el mismo, éste, en su correspondencia con John William Cooke, lo negó por no considerar al general Valle uno de los suyos y más aún, desautorizó el «golpe de Estado», como estrategia de lucha para el retorno. Ver: Melón Pirro, (2006): 67 a 77.

${ }^{18}$ Como atestiguan múltiples notas y denuncias recogidas por la prensa de oposición al gobierno provisorio y particularmente el discurso de las publicaciones clandestinas o semiclandestinas provenientes del peronismo.
} 
partidos menores, como el naciente Partido Demócrata Conservador Popular, sectores del nacionalismo y del comunismo que iniciaron una política de acercamiento y solidaridad con los proscriptos y de oposición al gobierno revolucionario.

El acontecimiento de mayor impacto político, a fines de 1956, fue la división de radicalismo. Esta, además de la lucha por el control del partido y el manejo de las candidaturas para las elecciones prometidas, reveló diferencias de concepción y estrategia políticas que los separaban desde tiempo atrás y se ahondaron en la situación creada por la Revolución Libertadora. Su razón fundamental fue la posición crítica de Arturo Frondizi frente al Gobierno Provisorio y su solidaridad con el peronismo, agravadas por la proximidad a Rogelio Frigerio, director de la revista Qué sucedió en 7 días, convertida desde temprano en portavoz de su candidatura presidencial.

Los sectores escindidos que pronto conformaron la Unión Cívica Radical del Pueblo, establecieron una alianza mucho más estrecha con el Gobierno Provisorio, sus hombres ocuparon los principales ministerios políticos en el gabinete nacional, Interior, Educación y Comunicaciones. De allí en más se puso en marcha el plan político en dos tiempos consistente en la convocatoria electoral para la Convención Constituyente ${ }^{19}$ previa a la elección del futuro gobierno que abrió una larga y competitiva campaña hasta febrero de 1958.

En el clima político de la época -y esto es interesante porque contrasta con la generalizada imagen de la «Libertadora» como el triunfo de los liberales-, por encima de los matices partidarios y de la reivindicación general de la tradición política, del Estado de Derecho y los principios democráticos, prevaleció un conjunto de valores y diagnósticos del país asociados al nacionalismo e intervencionismo económico y al antiimperialismo. ${ }^{20}$ Estos últimos eran visibles desde la etapa peronista, por ejemplo, en la oposición radical a la ratificación de las Actas de Chapultepec en 1946, a la Ley de Radicación de Capitales Extranjeros de 1953, ${ }^{21}$ como al famoso Contrato con la Standard Oil de California de

\footnotetext{
${ }^{19}$ El gobierno ambicionaba que ésta introdujera las reformas que evitaran a futuro recaer en nuevas dictaduras, atenuara el presidencialismo, aumentara las facultades del poder Legislativo e introdujera el régimen de representación electoral proporcional que asegurara la representación de las minorías.

${ }^{20}$ Baily, (1984); Solberg, (1982) y, sobre la coyuntura, Spinelli, (2003).

${ }^{21}$ Ley 14.222, derogada por Decreto Ley 16.640 de 1957.
} 
1955, también en las acusaciones que aparecieron en la campaña de panfletos del mismo año destinados a promover el derrocamiento del peronismo, ${ }^{22}$ denunciado, entre otros, la «entrega» de la Patagonia para la instalación de bases militares norteamericanas. Más adelante, en la oposición de la mayor parte de los partidos representados en la Junta Consultiva Nacional al «Plan Prebisch», en tanto proponía equilibrar las cuentas fiscales, suprimir los controles de precios y limitar los subsidios, incorporar capitales privados a la explotación petrolera y reinsertar al país en el mercado internacional promoviendo las exportaciones agropecuarias.

\section{La articulación de la estrategia desarrollista}

A grandes rasgos las aspiraciones políticas en el arco partidario pasaban por la restauración de la tradición política democrática y republicana, con la proscripción del peronismo en los sectores que apoyaban al gobierno provisorio y por el intento de captar el voto peronista para sus propios proyectos por parte de los opositores al mismo, allí se ubicaba el eje de la división radical. ${ }^{23}$ Las diferencias resultaban menos tajantes en el plano de la economía donde con matices prevalecía un nacionalismo económico de fuerte impronta antiimperialista y estatista, excepción hecha de los demócratas, sectores de la democracia progresista, del socialismo más tradicional ${ }^{24}$ y del recientemente formado Partido Cívico Independiente que orientaba el ingeniero Álvaro Alzogaray.

El peronismo, reprimido y expulsado de la legalidad, osciló entre la abstención promovida por el expresidente Perón desde el exilio y las tendencias participativas del neoperonismo, ${ }^{25}$ que se esforzó en adecuarse al Estatuto de los Partidos Políticos sancionado por el Gobierno Provisorio para alcanzar la legalidad.

\footnotetext{
${ }^{22}$ Lafiandra, (1955).

${ }^{23}$ Respecto a la división de la UCR: Rouquié, (1967); Odena, (1984); Gallo, (1983) y Acuña, (1984).

${ }^{24}$ Nos referimos a la que internamente se denominaba «Línea liberal» orientada por Américo Ghioldi, opuesta a los «Renovadores» o Línea de izquierda. Un pormenorizado análisis sobre las razones de la ruptura del Partido Socialista, concretada en julio de 1958, Tortti, (2009):59 a 107.

${ }^{25}$ Un sugestivo análisis de esta estrategia en Tcach, (2012): 67 a 85.
} 
En este contexto la Unión Cívica Radical Intransigente (en adelante UCRI), liderada por Arturo Frondizi y los sectores extrapartidarios que apoyaban su candidatura desde el grupo de la revista Qué sucedió en 7 días, se lanzaron a la conquista del voto peronista. La primera, desde los principios antiimperialistas de la Declaración de Avellaneda y la oposición al Gobierno, mientras los segundos lo hicieron proponiendo como objetivos el desarrollo económico, la paz social, la legalidad política para todos, iniciando un diálogo con sus dirigentes. Estas posiciones, cuyas diferencias provocaron las primeras tensiones internas, aunque no resultaron nítidas para la opinión pública en general, mostraron sus matices frente a la primera compulsa electoral del período, la elección de convencionales constituyentes de julio de 1957.

En esas elecciones, en las que se instauró excepcionalmente el Régimen de Representación Proporcional, obtuvo la primera minoría el voto en blanco, propiciado por el peronismo para repudiar al gobierno, segunda resultó la oficialista Unión Cívica Radical del Pueblo y tercera la opositora UCRI. Las dos agrupaciones radicales que inicialmente se habían opuesto a la Reforma Constitucional, finalmente participaron con objetivos distintos. La UCRP lo hizo como un servicio al gobierno del que formaba parte, llevando su propia plataforma electoral como proyecto de reforma, la UCRI para no dar quórum en la Asamblea e impedir la Reforma, con este argumento había buscado el voto peronista y competido con el voto en blanco. El tercer lugar, fue en consecuencia vivido como una derrota frente a sus antiguos correligionarios y como un fracaso en la conquista del voto peronista. A todo esto, Rogelio Frigerio desde la revista Qué... realizó un cálculo que lo llenaba de optimismo, sumó los votos en blanco a los votos de la UCRI y afirmó que el futuro presidente ya había sido consagrado.

Los contactos con Perón y con los peronistas exilados en Uruguay, Brasil y Chile, motorizados por los sectores extrapartidarios que apoyaron la candidatura de Frondizi, se intensificaron en los meses siguientes, ello trascendió a la prensa, alarmó al gobierno ${ }^{26}$ y a los partidos antiperonistas, dando un tono peculiar a la campaña electoral, donde el candidato de la UCRI fue acusado por la UCRP de representar un «pacto totalitario nazi-fascista-peronista-comunista».

\footnotetext{
${ }^{26}$ El momento culminante fue enero de 1958, cuando el Buenos Aires Herald informó sobre el encuentro entre Rogelio Frigerio y Juan Domingo Perón en Caracas, luego aclarado por la revista Qué...» a través de una nota titulada «Reportaje a Caracas».
} 
En el peronismo, con gran parte de sus dirigentes presos, escondidos o en el exilio y con otros ya lanzados a la carrera electoral, la opción por Frondizi era resistida. Ella constituía solo para algunos, una salida posible a la situación de hostigamiento y represión vivida desde el '55, visión que no era compartida por los sectores más combativos. ${ }^{27} \mathrm{El}$ establecimiento de algún tipo de acuerdo electoral trasladaba al seno del peronismo las mismas discusiones que se habían planteado en el radicalismo en tiempos de Perón, entre participación o abstención, que en la oportunidad, este finalmente dirimió a favor de la primera, volcando la elección a favor del candidato de la UCRI. Sin embargo, la conquista electoral estuvo plagada de peligros para el futuro gobierno.

Formalmente la puja electoral se dirimió entre los dos radicalismos y en las elecciones del 23 de febrero de 1958 triunfó el partido opositor al gobierno de la Revolución Libertadora, votado por buena parte del electorado peronista con el beneplácito del expresidente, según trascendió. Esto dio paso a una serie de cuestionamientos sobre la legitimidad de origen del nuevo gobierno constitucional.

\section{Los condicionantes del gobierno constitucional}

El gobierno de la Revolución Libertadora cumplió con su compromiso de llamar a elecciones y entregar el gobierno al partido ganador, aun cuando esa no fuera su vocación unánime. El conflicto en el interior del mismo sobre el rol histórico de la Revolución como «tumba de la tiranía» o como restauradora del orden constitucional no se había saldado cuando el presidente Aramburu -contra la opinión dominante en la Marina y en sectores minoritarios de las otras dos armas que habían intentado establecer otra proscripción- hizo prevalecer su hipótesis de que «la democracia solo se aprende en democracia» y reconoció el triunfo electoral de Arturo Frondizi, poniendo transitoriamente punto final al proceso revolucionario. ${ }^{28}$ Esta cuestión no saldada entre los «libertadores» se continuó dirimiendo en los años siguientes y fue una de las razones por las cuales las fuerzas armadas -con el respaldo de algunos

\footnotetext{
${ }^{27}$ Guardo, (1963): 97 a 104.

${ }^{28}$ Punto de partida de la línea Legalista dentro del ejército y del rol político asumido por el general Aramburu durante la gestión presidencial de Frondizi. Al respecto: Scenna, (1980), Rodríguez Lamas, (1984) y Toryho, (1973).
} 
de los partidos que habían apoyado la desperonización- en los hechos continuaron custodiando el poder conquistado en septiembre de 1955, uno de los factores que dificultaron la consolidación del régimen político constitucional. ${ }^{29}$

Hacia el final del Gobierno Provisorio, el periodismo político había acuñado tres términos para referirse a posiciones dominantes en lucha dentro del mismo. Mencionaron como «quedantistas» a aquellos que, con centro en la Marina, bregaban por la continuidad del gobierno de la Revolución Libertadora, hasta tanto se concretaran en su totalidad los objetivos de restauración de la tradición política y de exclusión del peronismo. «Continuistas» a quienes, compartiendo esos objetivos, pensaron concretarlos a través del apoyo a un partido político que los garantizara, en este caso la apuesta fue a la UCRP. Por último, el llamado «juego limpio» hacia el que, luego de oscilaciones, se inclinó el general Aramburu que mantenía como única condición la proscripción del peronismo, hecho que lo convirtió en el primer tramo de la etapa constitucional en virtual árbitro y negociador de la relación del gobierno con las fuerzas armadas.

El rasgo original de la Revolución Libertadora había sido la apuesta a la restauración democrática con la proscripción del peronismo como condición, hecho que, vistas las experiencias europeas luego de la derrota de los totalitarismos con las que muchos lo identificaban, no parecía irrealizable. Sin embargo, el gobierno peronista había sido derrocado por un golpe militar con una enorme adhesión civil, es cierto, pero no derrotado y dispersado. El partido, con su estructura y sus símbolos fue declarado fuera de la ley y eso se cumplió, pero el peronismo, entendido como el conjunto de ciudadanos que adherían a ese proyecto y cultura política, no se dispersó, mantuvo su identidad y siguió formando parte del electorado. Esta era la parte legalmente inmanejable de la apuesta democrática libertadora, la estrategia y la apelación de los candidatos que competían por el poder político frente al electorado no podían ser controladas por el gobierno revolucionario sin desnaturalizarla.

Arturo Frondizi, Rogelio Frigerio y el grupo desarrollista que los acompañó en la formulación de su proyecto político realizaron un diag-

\footnotetext{
${ }^{29}$ Uno de los primeros análisis sobre la lógica política de este proceso en la etapa 19551966, lo conceptualiza como poder arbitral o árbitro externo a la dinámica de partidos. O'Donnell, (1972) Sobre las relaciones de las fuerzas armadas con el gobierno en la etapa 1958-62, Rouquié, (1982): 99 a 190.
} 
nóstico de la coyuntura política nacional e internacional que analizaron y divulgaron a través de la revista Qué sucedió en 7 días desde comienzos de 1956. Priorizaron dos problemas, uno de índole política: el del peronismo, para el que, a diferencia de lo ejecutado por el Gobierno Provisorio postuló su incorporación a la legalidad política: ${ }^{30}$ la integración. El otro, que aún con menor intensidad había estado en debate desde la segunda presidencia de Perón y luego de su caída expuso Raúl Prebisch, era el económico: el déficit energético, el fiscal, la modernización del sector industrial, el problema de la productividad y el salarial. Para su solución cifraron todas las esperanzas en el programa desarrollista que convocaba al capital extranjero. Ambas líneas de solución fueron impugnadas por distintos sectores políticos y militares desde su inmediata puesta en marcha y no cedieron en los casi cuatro años de gestión presidencial.

Una de las polémicas más frecuentes en la historiografía y en la literatura política referida a la presidencia de Frondizi, por los costos políticos que tuvo para propios y extraños, fue el de la celebración del acuerdo con Perón ¿́Fue un error o una necesidad contemplada en el proyecto? Más allá de los términos del denominado Pacto Perón-Frondizi -hecho conocido en Buenos Aires y en el gobierno provisorio poco más de un mes antes de la elección de febrero, provocando un escándalo-, de si estuvo o no escrito, de si era o no legítimo reconocer la legalidad al peronismo una vez restaurado el Estado de Derecho o si esto constituía una violación a las condiciones impuestas por la Revolución Libertadora, cuya autoridad se proyectaba más allá del gobierno provisorio; de si efectivamente el candidato presidencial había autorizado a Rogelio Frigerio a firmarlo, o si, presionado por el expresidente o sin necesidad alguna lo hizo por iniciativa propia, ${ }^{31}$-cuestiones que volvieron al debate político cuando el dirigente de la UCRP, Miguel Ángel Zavala Ortíz, en una de las primeras manifestaciones opositoras al gobierno constitucional, lo denunció en julio de $1958^{32}$ y puso al presidente al borde del derrocamiento cuando Perón hizo lo propio en 1959, exponiendo su supuesto texto ante la prensa ${ }^{33}$-, lo cierto es que el mismo

\footnotetext{
${ }^{30}$ Una explicación sobre la centralidad del peronismo en el proceso político de inestabilidad política que siguió al derrocamiento de Perón, hasta 1973, Amaral, (1997): 325 a 360.

${ }^{31}$ Acusación que provino de la dirigencia de la UCRI, ver entre otros, Babini, (1984) y Alende, (1988):236 a 240.

${ }^{32}$ Smulovitz, (1988). El marco de la denuncia fue el acto convocado por la UCRP en Plaza Constitución bajo el lema: «Denunciamos la Entrega del País al Totalitarismo».

${ }^{33}$ Los términos del Pacto Perón-Frondizi se encuentran reproducidos entre otros, en Guar-
} 
condicionó desde el comienzo la relación del gobierno con el conjunto de los actores políticos.

Dentro del peronismo hubo distintas lecturas del Pacto. Algunos dirigentes pensaron que se trataría de un gobierno de transición dispuesto a sacrificarse, para llamar a nuevas elecciones y que Perón pudiera ser candidato ${ }^{34}$ otros que Frondizi se había «peronizado» y retomaría las «banderas» del peronismo, ${ }^{35}$ mientras los últimos advirtieron, entre ellos Perón, que no lo cumpliría y competiría políticamente con ellos. ${ }^{36}$ Inmediatamente al triunfo electoral se plantearon otras disyuntivas. Según expresaron algunos dirigentes, el voto peronista había sido solo contra

do, (1963) y en el Vol.II de la Correspondencia Perón-Cooke. (1973). A través del mismo Perón se comprometía a fijar su posición frente a la elección del 23 de febrero de 1958, declarando que los partidos neoperonistas que desearan pertenecer al movimiento debían retirar sus candidaturas, caso contrario serían separados del mismo, que dejaría en libertad de acción a la masa peronista para que sufrague en la forma que mejor exprese su repudio a la dictadura militar y a la política seguida por ella en todos los órdenes, aclarando que ello no implicaba compromiso alguno con los partidos que elijan para expresar su protesta. Mientras Frondizi se comprometía a restablecer las conquistas logradas por el pueblo, en los órdenes social, político y económico, revisando las medidas de carácter económico adoptadas desde el 16 de septiembre de 1955, entre las que se mencionan la reforma bancaria de 1946, una política económica de ocupación plena y amplio estímulo a la producción nacional, elevación del nivel de vida de las clases populares y afianzamiento de los regímenes de previsión social. La anulación de las medidas de persecución política, levantamiento de las interdicciones gremiales y restitución de los bienes a sus legítimos dueños, devolución de los bienes de la Fundación Eva Perón. Levantamiento de las inhabilitaciones gremiales y realización de los sindicatos y de la Confederación General del Trabajo, en un plazo de 120 días. Reconocimiento de la personería del Partido Peronista, devolución de sus bienes y levantamiento de las inhabilitaciones políticas, a cargo de las autoridades que designe el general Juan Domingo Perón. Reemplazo de los miembros de la Corte Suprema y eliminación de los magistrados que participaron en actos de persecución política. Convocar en el plazo de 2 años a una Convención Constituyente para la reforma total de la Constitución, que declarará la caducidad de todas las autoridades y llamará a elecciones generales. Por su parte, Perón se comprometía a interponer sus buenos oficios y su influencia política para lograr el clima pacífico y de colaboración popular indispensable para llevar a cabo los objetivos planteados. En la Correspondencia Perón-Cooke el texto, de 2 páginas, está fechado en febrero de 1958.

${ }^{34}$ Esta había sido la propuesta del Partido Demócrata Conservador Popular que orientaba el Dr. Vicente Solano Lima.

${ }^{35}$ Guardo, (1963): 106. Esta fue la posición del periódico Rebeldía que dirigía el padre Hernán Benítez, en Erlich, (2013).

${ }^{36}$ Monzón, (2006). En la correspondencia de Perón con Enrique Oliva, aparece una sugestiva frase que da cuenta de esta certeza por parte del primero en el siguiente diálogo:«Pero, mi general, perdóneme: iesto no lo van a cumplir Frondizi y su gente! - Claro, m’hijo. Y nosotros tampoco...Así es la cosa». 
el gobierno de los 'libertadores' y sus presuntos continuadores, no implicaba ningún tipo de compromiso con la UCRI, en consecuencia solo pedían igualdad con el resto de los ciudadanos. Otros, en cambio, consideraron que el voto peronista había resultado decisivo y ello les daba derecho a exigir la participación en la discusión de las políticas de gobierno e incluso a vetarlas. ${ }^{37}$

La transición desde el triunfo electoral del 23 de febrero hasta la entrega del gobierno el 1 de mayo de 1958 resultó muy compleja para el presidente electo y sus asesores más estrechos, dados los alineamientos de las Fuerzas Armadas en relación al mismo. Para la cúpula de la Marina Arturo Frondizi había transgredido los principios democráticos de la Revolución Libertadora y se negaba a entregarle el poder, posición que era compartida por sectores antiperonistas del Ejército y, en menor medida, de la Aeronáutica, renuentes a considerar que la democracia era también expresión de la soberanía popular. ${ }^{38}$ Aun así, prevaleció la decisión del presidente Aramburu de dar el gobierno a quien ganara la elección. Sin embargo, esto no evitó que la entrega estuviera condicionada a una serie de compromisos que el flamante presidente debió contraer con los sectores militares, entre ellos que no nombraría a peronistas ni comunistas en su gabinete o equipo de funcionarios. La acción de vigilancia ideológica y presión constante se prolongó durante los cuatro años que se mantuvo en el gobierno y el blanco de las sospechas fue el influyente extrapartidario Rogelio Frigerio, considerado la «eminencia gris» -era la expresión utilizada en el periodismo político más crítico- del proyecto integracionista.

Al problema de la relación con el peronismo, cuya naturaleza era desconocida por la mayor parte de la dirigencia de la UCRI, de sus militantes y simpatizantes que consideraban el apoyo electoral a Frondizi como espontáneo, ${ }^{39}$ se sumó aquel otro que la literatura política y buena parte de la historiografía concibió como el «cambio del programa». Este enfrentó al nacionalismo económico de la Declaración de Avellaneda,

\footnotetext{
${ }^{37}$ Entre ellos John William Cooke, uno de los testigos del Pacto. Spinelli, (2007).

${ }^{38}$ Ruíz Moreno, (1998): 222 cita una frase del Almirante Rojas que define esta línea política: «La Revolución Libertadora sucedió una vez, pero se produjo para siempre», a lo que agrega que «elementos militares y navales estaban completamente decididos a que se cumpliera tal sentencia. Era el sentir de la mayoría de los comandos, surgidos de ese movimiento, a despecho de pareceres de sentido más abierto».

${ }^{39}$ Ello se refleja en varios testimonios y en artículos de la época, Oscar Alende (1988), Babini (1984) y Troiani, (1958).
} 
también vigente en la plataforma electoral de la UCRP, con el ambicioso proyecto desarrollista, asentado en la modernización integral de la economía y las inversiones extranjeras como herramientas del crecimiento industrial acelerado, que había divulgado la revista Qué... y que Frondizi introdujo entre los ejes centrales de su discurso de campaña electoral, ${ }^{40}$ apartándose de la tradición radical de izquierda sobre la que había cimentado su imagen y su prestigio político. La apuesta era sumamente arriesgada porque desafiaba valores muy arraigados en la cultura política de los sectores medios y populares. Así, la búsqueda de una reinserción plena en el mercado mundial y la opción por el bloque occidental en el escenario de la Guerra Fría, ya iniciados durante el gobierno de la Revolución Libertadora, generaron rechazos muy marcados, tanto entre sus críticos, como en buena parte de los intelectuales y militantes de izquierda que habían trabajado políticamente para la UCRI ${ }^{41}$ y fueron los primeros desencantados.

Después de una gira por países de América Latina, Uruguay, Brasil, Perú y Chile, -en los que el presidente electo dio conferencias y reportajes, tomó contactó con sus gobernantes, presentó los objetivos de su proyecto de desarrollo e instó al diálogo, la colaboración y el intercambio $^{42}$ en los planos, económico, político, cultural y de las relaciones internacionales- se ultimaron los detalles para la asunción del 1 de mayo de 1958, en un clima de expectativas y censuras generado por la amplitud y naturaleza de su victoria electoral.

\footnotetext{
${ }^{40}$ Un análisis crítico sobre los lineamientos programáticos de los discursos de campaña de Arturo Frondizi, en Babini (1984):191-192, que resume en los siguientes términos: «Debe iniciarse una nueva etapa sin mirar hacia atrás, con la cooperación de cuantos compartan este programa sin distinción de banderías políticas. En lo económico deben integrarse el campo, la minería y la industria y acelerarse el desarrollo mediante el autoabastecimiento energético y el aporte del capital extranjero. En lo económico-social debe darse participación a trabajadores y empresarios en la discusión de los planes, a través de centrales únicas, debe haber un ministerio de Trabajo centralizado que asegure las conquistas sociales de los trabajadores. En lo educacional debe haber libertad de enseñanza. En la política exterior pertenecemos a Occidente y debemos participar en los organismos internacionales para asegurar la vigencia de un efectivo derecho internacional».

${ }^{41}$ Un ensayo emblemático de esta visión crítica, compuesto de 65 artículos periodísticos, publicados mayoritariamente en Marcha de Montevideo y algunos en Propósitos de Buenos Aires, es Selser, (1965). En la misma línea política de los intelectuales de la revista Contorno. ${ }^{42}$ Sobre esta experiencia puede verse el relato, de uno de sus colaboradores entonces más cercanos, Babini (1984): 215 a 219. Fragmentos de sus conferencias en Uruguay, en El Palacio de Itamaraty, en la Universidad de Santiago de Chile, en la Universidad de San Marcos, Lima, Perú, en Pisarello Virasoro, (2000): 107 a 122.
} 


\section{El acoso político y militar a la presidencia de Arturo Frondizi}

Con la asunción de Arturo Frondizi comenzó el difícil camino de una transición a la democracia, luego de la experiencia de 28 años de gobiernos militares y civiles que con distintos objetivos, revolucionarios o restauradores, habían suspendido las garantías constitucionales y coartado la libertad política a buena parte de la sociedad, ${ }^{43}$ en suma una larga secuencia de gobiernos excluyentes.

Los planes del novel presidente para esa transición pueden sintetizarse en la modernización integral del país, con dos objetivos claves, el desarrollo acelerado de la estructura económico-social para superar el atraso y la racionalización de la política. Las condiciones de la realidad conflictiva imperante convirtieron el desafío en una carrera de avances y retrocesos en la transformación, donde el norte fue el desarrollo.

En el discurso de inauguración del mandato ante la Asamblea Legislativa -a la que no asistieron los legisladores de la UCRP, la mayor fuerza de oposición con representación parlamentaria, ${ }^{44}$ como no volverían a hacerlo durante toda su gestión- el presidente expuso por primera vez de forma integral y sistemática el proyecto desarrollista en sus aspectos políticos y económicos. Respecto a los primeros expresó su intención de poner fin a las discordias del pasado reciente, de asegurar libertades políticas para todos, a través del dictado de una amplia amnistía ${ }^{45}$ y de abrir consultas con los dirigentes de todos los partidos. Se comprometió a que no habría partidismo en la función pública, ni en las Fuerzas Armadas y anunció una serie de reformas en la conformación de los ministerios secretarías y conducción de organismos del Estado, entre ellas que YPF pasaba a la órbita de la Presidencia. En su extensa exposición, que tuvo como eje el objetivo del desarrollo nacional detalló las formas en que éste se impulsaría en cada una de las áreas política, económica, social, cultural, en las fuerzas armadas y en la inserción internacional. Advirtió que no habría nuevas estatizaciones, ni vuelta atrás con las empresas estatales. Hizo alusión a la profundidad de la crisis económica, a la carencia de recursos para afrontar los compromisos contraídos por el Estado que tenían vencimientos próximos y al exceso de burocracia,

\footnotetext{
${ }^{43}$ Una explicación de este proceso, Rouquié, (1982): 65 a 76.

${ }^{44}$ Sobre un total de 187 diputados 133 representaban a la UCRI, 52 a la UCRP y 2 al Partido Liberal de Corrientes, en Smulovitz, (1988): 91.

${ }^{45} \mathrm{Su}$ proyecto fue el primero en ser girado al Congreso y la ley fue sancionada tres semanas después.
} 
sin detenerse en el análisis de sus causas. También expresó que llegaba al poder a través de comicios con inhabilitaciones y proscripciones, pero que esa conciencia no le impediría asumir en su totalidad las responsabilidades del cargo.

El plan de gobierno -que según diversos testimonios sorprendió y desilusionó a una parte de sus seguidores y agudizó el encono de sus opositores del radicalismo del pueblo que denunciaron la «trampa»con que les arrebató la elección- se puso inmediatamente en marcha, materializando primero las políticas que iban a generar mayores resistencias. Así, en la primera semana giró al Parlamento el proyecto de Ley de Amnistía que tuvo amplia cobertura de prensa y generó debates, dudas e impugnaciones sobre su alcance. Entre ellos sobresalió la preocupación de si alcanzaba o no a Perón, luego su impacto en las Fuerzas Armadas por las posibles reincorporaciones de oficiales y suboficiales retirados $\mathrm{o}$ dados de baja durante el gobierno provisorio que implicaba, igual que en las reparticiones públicas -salud, educación, banca estatal, serviciosdonde generó un marcado clima de hostilidad manifestado en huelgas, declaraciones y movilizaciones de repudio. Finalmente, en cuanto concernía a los partidarios de Perón, la ley de amnistía tampoco satisfizo porque, si bien liberaba a los presos políticos caducando sus causas, habilitaba el retorno de los exiliados y restituía los empleos de los que habían sido dejados cesantes por razones políticas, existían en algunos sectores expectativas mayores respecto al gobierno constitucional. Se ambicionaba que la misma alcanzara al expresidente y además se juzgara lo actuado durante la Revolución Libertadora: la represión, los fusilamientos, las interdicciones y la confiscación de los bienes de Perón, entre otros. La frustración peronista se vio agravada porque paralelamente a la sanción de esta ley, buscando establecer un equilibrio político con el antiperonismo, el gobierno envió otro proyecto de ley que otorgó el grado máximo en el escalafón de sus respectivas armas a los ex presidente y vicepresidente del Gobierno Provisorio, general Pedro Eugenio Aramburu y contralmirante Isaac Francisco Rojas, en un homenaje tributado a las fuerzas armadas en el Congreso de la Nación.

A continuación el presidente derogó los decretos de restricción a la actividad política y sindical del peronismo, sin alcanzar a restituir la legalidad del Partido Peronista ${ }^{46}$ y envió al Parlamento el proyecto de Ley de Asociaciones Profesionales que volvía a establecer un sindicato

46 Smulovitz, (1988): 39. 
por rama de actividad con vistas a la normalización de la CGT. Este último concretaba una de las propuestas de su campaña electoral de constituir un movimiento obrero fuerte y representativo, con el cual enfrentaba el objetivo de restablecer la libertad sindical de los partidos antiperonistas y conquistaba el apoyo de las «62» organizaciones peronistas. ${ }^{47}$ A lo que se agregó la restitución de la personería jurídica a la CGE que provocó el rechazo de la UIA, la Cámara Argentina de Comercio y la Bolsa de Comercio quienes pidieron que se garantice la libertad de agremiación. ${ }^{48}$

Esta primera fase, orientada a establecer la igualdad ante la ley al peronismo, tuvo altos costos para el gobierno que se elevaron de inmediato cuando anunció algunas de sus medidas económicas: primero, con el comienzo de la privatización de las empresas del grupo DINIE que culminó en 1962, ${ }^{49}$ medida que Rogelio Frigerio, su consultor más próximo en la materia, justificó después como una señal política necesaria a los capitales internacionales y, luego, con el anuncio, en julio de 1958, de la denominada «Batalla del petróleo», piedra angular del proyecto desarrollista, cuyo objetivo fue alcanzar el autoabastecimiento petrolero, mediante contratos de locación de obras celebrados por YPF con empresas petroleras internacionales. ${ }^{50} \mathrm{El}$ rechazo político fue estruendoso y no solo provino de sus opositores que reclamaron su debate parlamentario y denunciaron la «entrega de la soberanía», sino de sus propios partidarios que reclamaron el cumplimiento de las bases del Programa de Avellaneda. En cambio, recibió el apoyo de una significativa parte de la prensa nacional. Clarín, en nota editorial firmada por Roberto Noble, lo identificaba con los lineamientos de sus propias ideas sobre el tema y La Nación elogió la valentía del presidente de rectificar sus posiciones de 1954, expuestas en su libro Petróleo y política.

El escenario político del año 1958 continuó agitado por otra serie de iniciativas que rompían con principios y sentimientos muy arraigados en los sectores medios politizados que habían votado al gobierno. Un

\footnotetext{
47 Senén González, (1971):22-23.

${ }^{48}$ Clarin, 09/06/1958, pág.9: «Satisfacción, desacuerdo y reservas ante una medida. Opiniones encontradas provoca la restitución de la Personería Jurídica a la CGE».

${ }^{49}$ Las tratativas con las empresas alemanas habían sido iniciadas durante la gestión del gobierno provisorio del general Aramburu en el marco de la reinserción argentina en la economía internacional. Un análisis específico, Belini (2008): 93-134.

${ }^{50} \mathrm{El}$ tema petrolero y los acuerdos para los contratos estuvieron en la prensa desde mediados del mes de mayo de 1958 hasta fines octubre.
} 
ejemplo de ello fue el enfrentamiento que rodeó a la sanción de la Ley de Educación Libre que autorizaba el otorgamiento de títulos por parte de las Universidades Privadas rompiendo con el monopolio estatal de la enseñanza ${ }^{51}$ y que motivó, además de estruendosas movilizaciones, la primera ruptura dentro del bloque de diputados de la UCRI.

El gobierno y particularmente la imagen del presidente sufrieron un prematuro desgaste por el impacto de sus principales medidas políticas y económicas que le enajenaron la neutralidad del peronismo, ${ }^{52}$ aquellas que intentaban atacar el déficit fiscal y que llevaron también a la oposición a sectores de la UCRI, en medio de un creciente proceso inflacionario y de déficit de la balanza de pagos. La oposición ensayó diversas estrategias, desde la denuncia de «entrega» del país, que volvió a reflotar a raíz del debate parlamentario por la ley de radicación de capitales extranjeros. A la conspiración para el derrocamiento del presidente, que salpicó al vicepresidente Alejandro Gómez precipitando su renuncia a fines de 1958, se sumó una fiscalización ideológica estricta por parte de sectores de la oficialidad de las fuerzas armadas, crítica de la presencia de algunos funcionarios sospechados de comunistas y particularmente del Secretario de Relaciones Económico-Sociales, el extrapartidario Rogelio Frigerio, cuya renuncia forzaron hacia fin de año. ${ }^{53}$

La confrontación política persistió durante todo el año siguiente, cuando el presidente realizó el primer viaje a los Estados Unidos, con dos picos de tensión con el peronismo de gran impacto en la opinión pública y en la estabilidad del gobierno. El primero, liderado por los sectores más radicalizados del mismo, fue la toma del Frigorífico Lisandro de la Torre y sus secuelas de represión. ${ }^{54}$ El segundo, la denuncia del

\footnotetext{
${ }^{51} \mathrm{El}$ tema ha sido vastamente tratado por la historiografía argentina. Entre otros, Terán, (1991): 131-132; Sarlo, (2001):63-71; y Suasnábar, (2004): 47-64.

${ }^{52}$ Correo de la Tarde, 12-12-1958, p.4: «El gobierno no cumple con sus compromisos, dicen los peronistas» en un documento del Consejo Coordinador y Supervisor del Peronismo, entre otros, dice que el gobierno no ha cumplido con sus compromisos preelectorales y que ha perdido toda consideración y confianza por parte del electorado peronista que ha pasado a la oposición.

${ }^{53}$ El diario Correo de la Tarde del 27-11-1958 publicó las cartas entre Frondizi y Frigerio, en las que el presidente le agradece la firma de los acuerdos de YPF y el replanteo y coordinación de la política económica, en tanto Frigerio le dice, entre otros: «... mi retiro beneficia más a la causa que ambos servimos que mi permanencia en el cargo -a lo que agrega: En estos momentos se intenta derrumbar esa casi milagrosa conquista de la normalidad institucional»

${ }^{54}$ Un análisis sobre este acontecimiento desde las razones de los trabajadores y el ideario peronista, Salas, (2015).
} 
«Pacto» de 1958 por parte de Perón que el presidente negó ${ }^{55}$ y denunció, vinculándolo a un plan para alterar el orden constitucional y frustrar el plan de desarrollo económico. ${ }^{56}$

En ese contexto de debilidad política del gobierno jaqueado por una ampliada oposición política y la presión militar, se puso en marcha el Plan CONINTES. ${ }^{57}$ Además, la crisis económica que había llevado a la implementación de un plan de austeridad para intentar paliar el déficit fiscal y controlar la inflación, trató de revertirse con la implementación de un más decidido plan denominado de «Estabilización y Desarrollo» en el marco del primer empréstito contraído con el FMI. Dicho plan estuvo a cargo del ingeniero Álvaro Alzogaray -ajeno al equipo de colaboradores del presidente y más liberal que desarrollista, según su propia definición-, cuya gestión como ministro de Economía y de Trabajo se prolongó hasta $1961 .{ }^{58}$ En este período, en virtud de una batería de medidas mucho más ortodoxas, se produjo una recuperación de la actividad económica ligada a la retracción de la inflación y al significativo aumento de la inversión..$^{59}$ Cabe destacar que una de las constantes de la política económica a lo largo de toda la gestión presidencial desarrollista fue la promoción industrial y regional traducida en una dinamización de la economía y los negocios. ${ }^{60}$

\footnotetext{
${ }^{55}$ La Prensa, 12/06/1959: «Niega el gobierno haber hecho cualquier pacto preelectoral. Lo afirmó el Ministro del Interior Dr. A. Vítolo, a raíz de las declaraciones que hicieran adictos al exdictador. Este, por su parte, sostiene que existió y que ahora lo denuncia», continúa en página 3 la conferencia de prensa del Ministro Vítolo, el día 15/06/1959 La Prensa: «El presidente negó la firma del pacto», dice que su firma ha sido falsificada. En carta al Ministro Vítolo dice, entre otras, que junto al texto el ex dictador depuesto ha distribuido incitaciones a la insurrección, por «lo que creo indispensable que se advierta al país que no existe posibilidad alguna de restauración y que vamos a actuar con inflexible severidad con los que procuran subvertir las instituciones y crear el caos...»

${ }^{56}$ La Prensa, 19/06/1959: «El Dr. Vítolo denunció que se intenta derrocar al gobierno. Lo hizo después de medianoche en Diputados. La Cámara declaró ayer que no hubo pacto». ${ }^{57}$ Correo de la Tarde, 21/01/1959: «Apóyase el gobierno en las Fuerzas Armadas» sostiene que con el plan CONINTES el peronismo y el comunismo serán declarados fuera de la ley y que en esta decisión tuvieron profunda gravitación los integrantes del gabinete militar.

${ }^{58}$ Las versiones de los propios actores difieren respecto de la llegada de Álvaro Alzogaray al ministerio. Frondizi sostuvo que su elección estuvo motivada por la crisis militar y el nombre del Ingeniero resultaba potable dados sus nexos familiares y políticos con el Ejército, otras versiones sostienen que fue idea de Rogelio Frigerio.

${ }^{59}$ Gerchunoff y Llach, (1998): 265 a 278.

${ }^{60}$ De Pablo, (2005) realiza un exhaustivo relevamiento de los decretos del Poder Ejecutivo desde 1958 a comienzos de 1962.
} 
La otra pieza crucial del proyecto desarrollista -combatida intelectual y políticamente por distintos sectores de la opinión civil y militar- fue la política exterior. Definida por sus impulsores como occidental -porque retomaba la tradición histórica democrática que la unía a Europa- e independiente en el continente americano. En este espacio priorizó relaciones político-económicas fluidas con Estados Unidos y trabajó en el establecimiento de acuerdos de cooperación y consulta permanentes con las naciones del Cono Sur y con México, a lo largo de los cuatro años.

Respecto a la ubicación del país en el contexto de la Guerra Fría, el gobierno de Frondizi no se apartó de la línea iniciada por la Revolución Libertadora que abandonó el «tercerismo» y el aislacionismo peronista, ubicándose en el Bloque Occidental. Esto fue censurado por la izquierda antiimperialista y por el radicalismo del pueblo, solidarios con los procesos de descolonización europeos, que denunciaron una conspiración de dominación norteamericana, vía los contratos petroleros, «que convierten a los «mandatarios» de centro y Sudamérica, en los manager de los intereses norteamericanos en sus respectivas patrias». ${ }^{61}$

El alineamiento con Occidente no fue obstáculo para mantener activas relaciones con la Unión Soviética, China Comunista y los países del Este, lo cual despertó inquietud de sectores civiles y militares inscriptos ideológicamente en el centro-derecha, severos críticos de Rogelio Frigerio, sospechado de haber operado en la Cancillería desde los inicios de la gestión presidencial, a través del nombramiento de Carlos Florit, ${ }^{62}$ que continuó en el cargo hasta la salida del primero del gobierno, avanzado el año 1959. El retorno de su influencia a partir de la segunda mitad de 1961 fue identificado con lo que estos sectores percibieron como un viraje internacional que implicaba el abandono de la posición occidental y un acercamiento a la Cuba de Castro. ${ }^{63}$

\footnotetext{
${ }^{61}$ Marcha, Montevideo, 30/01/1959: «Un documento sensacional. Gabriel a la enésima potencia» por Ventura Joffe.

${ }_{62}$ El integrante más joven del gabinete de Frondizi, abogado, periodista y docente de la Facultad de Derecho de la Universidad de Buenos Aires. De formación nacionalista. Su visión del orden mundial en Florit, (1960).

${ }^{63}$ El Príncipe, Septiembre de 1961: «La cancillería a la deriva», págs. 66 a 69, ver también Atlántida, enero de 1962, en el balance del año 1961 escrito por Mariano Grondona menciona «la nueva política» de la alianza argentino-brasileña que marca la influencia del «sector integracionista».
} 
La adhesión de la revolución cubana al marxismo y a la órbita soviética conmocionó a la opinión pública -que inicialmente había apoyado el derrocamiento de Fulgencio Batista como un triunfo de la democracia y recibido de buen grado la visita de Fidel Castro en 1959- y sembró de sospechas cualquier intento de racionalizar o discutir la situación que no implicara su aislamiento liso y 1 lano ${ }^{64}$, en momentos que también se especulaba con el giro del peronismo a la «extrema izquierda». Desde el punto de vista de las relaciones interamericanas, el gobierno había reforzado desde su inicio una tendencia al diálogo y al establecimiento de acuerdos sobre problemas comunes, con sus pares latinoamericanos, fundamentalmente selló un acuerdo de cooperación y diálogo con Brasil, del mismo modo que buscó preservar y fortalecer la relación con los Estados Unidos en ese contexto. ${ }^{65}$ En este plano se inscriben acontecimientos como la Conferencia de Uruguayana (abril de 1961), entre los presidentes Arturo Frondizi y Janio Quadros, donde se discutieron las bases de políticas internacionales comunes y la adhesión a la Alianza para el Progreso, concretada poco después en la reunión del CIES (Consejo Interamericano Económico y Social) en Punta del Este. Este proceso culminó en una severa crisis militar -a raíz del incidente de una entrevista que pretendió ser secreta con el Ministro de Industria cubano, el argentino Ernesto «Che» Guevara, luego condecorado en Brasil- agudizada luego por la abstención de la Cancillería argentina en la reunión de la OEA en Punta del Este que expulsó a Cuba, hasta forzar al gobierno a declarar la ruptura de relaciones con La Habana.

El gobierno desarrollista había llegado a su fin cuando el clima de la Guerra Fría se instaló plenamente en la política argentina y particularmente en las fuerzas armadas, ello fue visible en la prensa que con matices venía condenando desde tiempo atrás los fusilamientos y los métodos de presión de la revolución cubana. Hostigado por las fuerzas armadas y una abrumadora oposición partidaria, solo faltaban las elecciones de marzo de 1962 y el triunfo de los candidatos peronistas en la Provincia de Buenos Aires. ${ }^{66}$

\footnotetext{
${ }^{64}$ Hubo una serie de operaciones políticas contra las posiciones del gobierno en torno a Cuba, entre ellas el famoso episodio de las fraguadas «cartas cubanas», denunciadas durante la visita de Frondizi al presidente Kennedy, Estados Unidos en 1961.

${ }^{65}$ Entre otros, Llairó y Siepe, (2003) y Amicci, (2012).

${ }^{66}$ Sobre la caída de Frondizi y la llegada a la presidencia de José María Guido, Hudson, (2014).
} 


\section{Conclusiones}

La Revolución Libertadora abrió una nueva fase de crisis política porque no logró consensuar entre las fuerzas armadas que ejercían el poder un proyecto político de transición. Las ideas sobre el rol y el qué hacer de la revolución estuvieron en constante puja durante sus dos años y medio de vigencia. Luego del llamado a elecciones, el Gobierno Provisorio de Aramburu y Rojas fue derrotado por un conjunto heterogéneo grupos opositores que bajo el nombre de la UCRI y aliados transitoriamente con el peronismo intentaron otra solución, integral y transformadora de la estructura económica y social que nació plagada de obstáculos en un contexto político hostil.

En nuestro análisis de la llegada al gobierno y la gestión presidencial de Arturo Frondizi hemos explorado en tres aspectos políticos cruciales en el desenlace de su fracaso político.

Los costos del «pacto con Perón» para el gobierno constitucional fueron altísimos. Frente al antiperonismo político, porque lo convirtió en un competidor ilegítimo y por ende en el motivo que justificaba recurrir a la oposición desleal (golpista) en nombre de la democracia. Ya para el 16 de setiembre de 1958, tercer aniversario de la Revolución Libertadora, la UCRP reclamó el «derecho a la revolución». Frente a las fuerzas armadas, momentáneamente derrotados los sectores que querían impedir la entrega del gobierno a raíz del mismo, las consolidó en su auto asignado rol de fiscalización y presión sobre el mismo. Con el peronismo, generó una situación equívoca, similar a la del deudor incobrable frente al acreedor, porque el discutido acuerdo electoral no implicaba en la interpretación de Frondizi y de Frigerio, una sociedad política con el mismo, pero sí un compromiso cuyo cumplimiento Perón vigiló escrupulosamente ampliando plazos, durante poco más de un año, hasta que rompió. Otra derivación involucró la puesta en marcha del proyecto desarrollista y las políticas económicas adoptadas, que afectaron la relación con su actor más dinámico y potente, el sindicalismo peronista. Esta alternó entre el conflicto, la negociación y la represión. Un elemento, vinculado al anterior y no menos importante estaba constituido por la necesidad de desmontar el fuerte intervencionismo económico construido por el peronismo, visible en el manejo de las empresas estatales, tarea ímproba si las había que también chocaba con la UCRI y el programa de Avellaneda, pero que fue particularmente conflictivo en su rela- 
ción con los sectores sindicales que definieron al gobierno como su principal enemigo.

El proyecto modernizador de la estructura económica y social en clave capitalista del Desarrollismo, con su apelación a la inversión de capital extranjero y la centralidad en el desarrollo petrolero y la industria pesada, si bien logró en gran medida implementarse y perduró en el largo plazo, ${ }^{67}$ resultó política y moralmente impugnado por el extendido sentimiento nacionalista que atravesó a partidos y grupos de opinión, a derecha e izquierda del espectro ideológico. A esto debe sumarse la coyuntura económica crítica con altos índices de inflación y déficit fiscal que afectaron el nivel de vida de los trabajadores y no lograron revertirse en los primeros dos años, multiplicando conflictos sociales y minando la ya escasa credibilidad del gobierno.

Por último, la conducción de la política exterior. Aspecto fundamental del proyecto desarrollista que persiguió una nueva inserción en el mapa mundial y un mayor protagonismo del país y de América Latina en la relación con Estados Unidos, según los argumentos esbozados por sus gestores, resultó eficazmente obstruida por sus impugnadores. En el contexto del impacto de la Guerra Fría en América Latina, esta entró en tensión con las fuerzas armadas, con la mayoría de los partidos políticos y de gravitantes sectores de opinión que vieron en ella el peligro de un giro denunciado como pro-cubano.

\section{Bibliografía}

ACUÑA, Marcelo Luis, (1984), De Frondizi a Alfonsin: la tradición politica del radicalismo. Buenos Aires: Centro Editor de América Latina.

ALENDE, Oscar, (1988), Mi memoria. Buenos Aires: Planeta.

AMARAL, Samuel ,(1993), «El avión negro: retórica y práctica de la violencia», en AMARAL, Samuel y PLOTKIN, Mariano Ben, $\mathrm{Pe}$ rón del exilio al poder. Buenos Aires: Cántaro.

\footnotetext{
${ }^{67}$ Una explicación desarrollada en este sentido, Juan Carlos Portantiero (1989): «Economía y política en la crisis argentina (1958-1973)», en Waldo Ansaldi y José Luis Moreno: Estado y sociedad en el pensamiento nacional, Buenos Aires, Cántaro. También se corrobora en los argumentos de Hardoy (1993): 314 -318.
} 
AMARAL, Samuel, (1997), «De Perón a Perón (1955-1973)», Nueva Historia de la Nación Argentina 7, la Argentina del siglo XX. Buenos Aires: Academia Nacional de la Historia.

AMICCI, Daniel, (2012), «La trayectoria hacia la Cumbre de Uruguayana: máxima expresión de la aproximación entre Argentina y Brasil durante el desarrollismo», en Confines 8/15.

BABINI, Nicolás, (1984), Frondizi De la oposición al Gobierno, Buenos Aires:

BAILY, Samuel, (1984), Movimiento obrero, nacionalismo y politica en la Argentina. Buenos Aires: Paidós.

BELINI, Claudio y ROUGIER, Marcelo, (2008), El Estado empresario en la industria argentina. Conformación y crisis. Buenos Aires: Manantial.

BUSTOS FIERRO, Raúl, (1969), Desde Perón hasta Onganía. Buenos Aires: Octubre.

D'ABATE, Juan Carlos, (2003), Framini-Perón. Elecciones del 18 de marzo de 1962 en la Provincia de Buenos Aires. Barcelona: PPU.

DE FERRARIS, Agustín, (1956), Pido la palabra.

DE PABLO, Juan Carlos, (2005), La economia argentina en la segunda mitad del siglo XX. Buenos Aires: La Ley.

ERLICH, Laura, (2013), Intransigentes, duros y revolucionarios. Variaciones en la cultura politica peronista entre 1955 y 1973. Tesis Doctoral Inédita, Facultad de Filosofía y Letras, Universidad de Buenos Aires.

FERLA, Salvador, (1964), Mártires y verdugos. Buenos Aires: Peña Lillo.

FLORIT, Carlos, (1960), Politica exterior nacional. Buenos Aires: Arayú.

GALLO, Ricardo, (1983), 1956-1958 Balbín, Frondizi y la división del radicalismo. Buenos Aires: Editorial de Belgrano.

GARCÍA, Eduardo Augusto, (1971), Yo fui testigo. Antes, durante y después de la Segunda Tiranía. Buenos Aires.

GERCHUNOFF, Pablo y LLACH, Lucas, (1998), El ciclo de la ilusión y el desencanto. Un siglo de politicas económicas argentinas. Buenos Aires: Ariel. 
GONZÁLEZ CRESPO, Jorge, (1993), Memorias del Almirante Isaac F. Rojas. Buenos Aires: Planeta.

GOÑI MORENO, José, (1967), La hora decisiva. Buenos Aires: Peña Lillo.

GUARDO, Ricardo, (1963), Horas difíciles. Buenos Aires: s/ ed.

HARDOY, Emilio, (1993), No he vivido en vano (memorias). Buenos Aires: Marymar.

HUDSON, Carlos, (2014), «Un golpe muy particular. Problemas políticos en la crisis del gobierno de Arturo Frondizi y la presidencia de José María Guido» (Tesis Doctoral inédita).

JÁUREGUI, Aníbal, CERRA, Angel y YAZBEC, Susana, (2016), Génesis y construcción del desarrollismo argentino. Buenos Aires: Biblos.

JAURETCHE, Arturo, (1957), Los profetas del odio. Buenos Aires: Peña Lillo.

LAFIANDRA, Felix, (1955), Los panfletos. Su aporte a la Revolución Libertadora, Buenos Aires: Itinerarium.

LANUSSE, Alejandro, (1988), Protagonista y testigo (Reflexiones sobre 70 años de nuestra historia). Buenos Aires: Marcelo Lugones.

LLAIRÓ, María Monserrat y SIEPE, Raimundo, (2003), Frondizi. Un nuevo modelo de inserción internacional. Buenos Aires: Eudeba.

MALLON, Richard y SOURROUILE, Juan, (1973), La politica económica en una sociedad conflictiva. El caso argentino. Buenos Aires: Amorrortu.

MELÓN PIRRO, Julio César, (2006), El peronismo después del peronismo. Resistencia, sindicalismo y política luego del 55. Buenos Aires: Siglo XXI.

MONZÓN, Florencio, (2006), Llegó carta de Perón. Rapsodia de la Resistencia. Buenos Aires: Corregidor.

O'DONNELL, Guillermo, (1972), «Un juego imposible. Competencias y coaliciones entre partidos políticos en Argentina, 1955-1966» en O'DONNELL, Guillermo, Modernización y autoritarismo. Buenos Aires: Paidós

ODENA, Isidro, (1984), Libertadores y desarrollistas, 1955-1962. Buenos Aires: La Bastilla.

PERREN, Jorge, (1997), Puerto Belgrano y la Revolución Libertadora. Buenos Aires: Solaris. 
PISARELLO VIRASORO, Roberto, (2000), Arturo Frondizi, su pensamiento. Buenos Aires: edición del autor.

POTASH, Robert, (1981), El ejército y la politica en la Argentina 19451962. De Perón a Frondizi., Buenos Aires: Sudamericana.

RODRÍGUEZ LAMAS, Daniel, (1984), La presidencia de Frondizi. Buenos Aires: Centro Editor de América Latina.

ROUQUIÉ, Alain, (1967), Radicales y desarrollistas. Buenos Aires: Schapire.

ROUQUIÉ, Alain, (1982), «El poder militar en la Argentina de hoy: cambio y continuidad», en WALDMAN, Peter y GARZÓN VALDÉZ, Ernesto El poder militar en la Argentina 1976-1981. Buenos Aires: Galerna.

ROUQUIÉ, Alain, (1982), Poder militar y sociedad politica en la Argentina II 1943-1973. Buenos Aires: Emecé.

RUÍZ MORENO, Isidoro, (1998), La Marina revolucionaria, 18741963. Buenos Aires: Planeta.

SALAS, Ernesto José, (2015), La resistencia peronista. La toma del frigorifico Lisandro de la Torre. Buenos Aires: Punto de Encuentro.

SÁNCHEZ ZINNY, Eduardo, (1958), El culto de la infamia. Historia documentada de la Segunda Tiranía argentina. Buenos Aires: Gure.

SARLO, Beatríz, (2001), La batalla de las ideas (1943- 1973). Biblioteca del Pensamiento Argentino VII. Buenos Aires: Ariel.

SCENNA, Miguel Angel, (1980), Los militares. Buenos Aires: Editorial de Belgrano.

SELSER, Gregorio, (1965), Argentina a precio de costo. El gobierno de Frondizi. Buenos Aires: Iguazú.

SENÉN GONZÁLEZ, Santiago, (1971), El sindicalismo después de Perón. Buenos Aires: Galerna.

SIKKIN, Kathryn, (2009), El proyecto desarrollista en la Argentina y Brasil: Frondizi y Kubitschek. Buenos Aires: Siglo XXI.

SMULOVITZ, Catalina, (1988), Oposición y gobierno: los años de Frondi$z i / 1$. Buenos Aires: Centro Editor de América Latina.

SOLBERG, Carl, (1982), Petróleo y nacionalismo en la Argentina. Buenos Aires: Emecé.

SPINELLI, María Estela, (2003), «Ideas fuerza en el debate político durante los años de la 'Libertadora', 1955-1958", en Estudios Socia- 
les 24. Santa Fe: Universidad Nacional del Litoral.

SPINELLI, María Estela, (2004): «La otra multitud. Las movilizaciones antiperonistas durante la Revolución Libertadora», en Desarrollo Económico 172.pp 609 a 635.

SPINELLI, María Estela, (2005), Los vencedores vencidos. El antiperonismo y la «revolución libertadora, 1955-1958, Buenos Aires: Biblos.

SPINELLI, María Estela, (2007), «Las revistas Qué sucedió en 7 dias y Mayoría. El enfrentamiento en el antiperonismo durante los primeros años del 'frondizismo'», en DA ORDEN, María Liliana y MELÓN PIRRO, Julio César: Prensa y peronismo. Discursos, prácticas, empresas 1943-1958. Rosario: Prohistoria.

SPINELLI, María Estela, (2012), « La Ley Saenz Peña otra vez en debate: la «Revolución Libertadora», 1955-1958", en Estudios sociales 43. Santa Fe: UNL. pp 133 a 146.

SUASNÁBAR, Claudio, (2004), Universidad e intelectuales. Educación y politica en la Argentina (1955-1976). Buenos Aires: Flacso Manantial.

TCACH, César, (2012), De la Revolución Libertadora al Cordobazo. Buenos Aires: Siglo XXI.

TERÁN, Oscar, (1991), Nuestros años sesentas. Buenos Aires: Puntosur.

TORTTI, María Cristina, (2009), El 'viejo’ partido socialista y los orígenes de la 'nueva izquierda'. Buenos Aires: Prometeo.

TORYHO, Jacinto, (1973), Aramburu. Confidencias. Actitudes. Propósitos. Buenos Aires: Libera.

TROIANI, Osiris, «Por qué Perón hizo votar por Frondizi», Mayoría, $\mathrm{N}^{\circ} 57,12 / 05 / 1958$.

WALSH, Rodolfo, (1957), Operación masacre. Buenos Aires: Sigla. 